\title{
Exigências de aminoácidos sulfurados digestíveis para suínos machos castrados e fêmeas de 15 a $30 \mathbf{k g}^{1}$
}

\author{
Jaqueline de Oliveira Moura ${ }^{2}$, Paulo César Brustolini ${ }^{3}$, Francisco Carlos de Oliveira Silva ${ }^{4}$, \\ Juarez Lopes Donzele ${ }^{3}$, Aloízio Soares Ferreira ${ }^{3}$, Eriane de Paula ${ }^{5}$
}

\author{
${ }^{1}$ Parte da tese de mestrado do primeiro autor. \\ ${ }^{2}$ Mestrando em Zootecnia - UFV. \\ ${ }^{3}$ Departamento de Zootecnia - UFV. \\ 4 EPAMIG. \\ ${ }^{5}$ Graduação em Zootecnia - UFV.
}

RESUMO - Cinqüenta leitões mestiços (Landrace x Large White), sendo 25 machos castrados e 25 fêmeas, na fase inicial de crescimento (15 a $30 \mathrm{~kg}$ ), foram utilizados em um experimento visando determinar a exigência de aminoácidos sulfurados digestíveis. Os animais foram distribuídos em delineamento experimental de blocos ao acaso, com cinco tratamentos $(0,502$; 0,$530 ; 0,558 ; 0,586$ e $0,614 \%$ de metionina + cistina digestível), cinco repetições e dois animais, um macho e uma fêmea, por unidade experimental. Os níveis de metionina + cistina digestível da ração influenciaram de forma quadrática o ganho de peso diário (GPD) dos animais, que aumentou até o nível de $0,582 \%$; a conversão alimentar (CA), que reduziu até o nível de 0,588\%; e o consumo diário de ração (CDR), que aumentou até o nível de $0,579 \%$. Os tratamentos influenciaram a deposição de gordura (DG), que variou de forma quadrática, reduzindo até o nível de $0,556 \%$, mas não alteraram a deposição de proteína (DP). A exigência de aminoácidos sulfurados digestíveis para suínos machos castrados e fêmeas de 15 a $30 \mathrm{~kg}$, para maior ganho de peso, é de $0,582 \%$ e, para menor conversão alimentar, de $0,588 \%$ de metionina + cistina digestível na ração, correspondendo a uma relação de $63 \%$ de metionina + cistina digestível:lisina digestível.

Palavras-chaves: aminoácido digestível, carcaça, exigência, fase inicial, genótipo

\section{Digestible sulfur amino acids requirements for barrows and gilts from 15 to $30 \mathrm{~kg}$}

\begin{abstract}
A trial was conducted with fifty pigs (Landrace x Large White), barrows and gilts, from 15 to $30 \mathrm{~kg}$, in the initial growing phase to determine the digestible sulfur amino acids requirements. The animals were allotted to a completely randomized experimental block design, with five treatments $(0.502,0.530,0.558,0.586$, and $0.614 \%$ of digestible methionine plus cystine), five replicates and two animals (one male and one female) per experimental unit. It was observed quadract effect of treatments on daily weight gain, that increased up to the level of $0.582 \%$, on feed:gain ratio, that decreased up to the level of $0.588 \%$, and on daily feed intake, that increased up to the level of $0.579 \%$. The intake of digestible methionine and cystine linearly increased as the dietary levels of digestible methionine plus cystine increased. It was observed quadract treatment effect on fat deposition, that increased up to the level of $0.556 \%$, but no treatment effect on protein deposition was detected. It was concluded that the digestible sulfur amino acid requirement for barrows and gilts from 15 to the $30 \mathrm{~kg}$ is of 0.582 and $0.588 \%$, that corresponds to a digestible methionine plus cystine:digestible lysine ratio of $63 \%$, respectively, for the highest weight gain and lowest feed:gain ratio.
\end{abstract}

Key Words: genotype, initial phase, digestible amino acid, requirement

\section{Introdução}

Na composição das dietas tradicionais no Brasil, à base de milho e farelo de soja, a metionina + cistina são consideradas o segundo aminoácido limitante para suínos em crescimento, principalmente quando o objetivo é maximizar o crescimento e o desenvolvimento desses animais (Leibholz, 1984).

Sabe-se que a expressão gênica, além dos efeitos ambientais, sociais e sanitários, pode exercer efeitos primários sobre o desempenho animal se as exigências nutricionais não forem devidamente atendidas e que a subnutrição opõe-se à produtividade, afetando a qualidade do produto. Entretanto, a provisão excessiva de nutrientes pode ser ainda mais onerosa que as deficiências, por limitar a produção e, concomitantemente, elevar o custo da alimentação.

Nos últimos anos, a alta demanda dos consumidores e da indústria por carne suína com pouca gordura tem estimulado as grandes empresas suinícolas à maximização do crescimento 
cárneo dos suínos por meio do melhoramento genético. Além disso, as rações práticas utilizadas são formuladas à base de milho e farelo de soja para atender à exigência dos animais em lisina, resultando em rações com nível protéico acima das necessidades dos animais e contendo quantidades excessivas de alguns aminoácidos.

O excesso de proteína e aminoácidos, ao ser catabolizado, provoca sobrecarga, principalmente no fígado e nos rins, no processo de eliminação de nitrogênio. Como conseqüência, pode ocorrer aumento na produção de calor metabólico, o que, em condições de temperaturas elevadas, como normalmente ocorre no Brasil, faz com que o animal reduza a quantidade ingerida de alimento e de outros nutrientes indispensáveis para a produção.

Por isso, o aumento do teor de PB das dietas de animais de baixo consumo alimentar voluntário pode ser prejudicial. Os aminoácidos dietéticos, quando fornecidos em excesso, são utilizados de forma metabólica ineficiente. Ao serem desaminados, emitem grandes quantidades de energia calórica, ocasionando redução significativa da energia líquida disponível, prejudicando a eficiência na síntese de tecido magro.

Assim, o correto balanço de aminoácidos das dietas pode contribuir para o aumento da retenção e para a redução da excreção corporal de nitrogênio (Pfeiffer \& Henkel, 1991, citados por Nones, 1999). O balanço de aminoácidos das dietas também pode possibilitar a redução da quantidade total de dejetos produzidos, por meio da redução do consumo de água e da melhora da eficiência alimentar, minimizando a poluição ambiental causada pela atividade suinícola.

Entretanto, a diversificação nas respostas dos suínos aos diferentes planos nutricionais e aos diferentes ambientes a que são submetidos tem sugerido que novas pesquisas precisam ser realizadas visando determinar padrões de alimentação econômicos e tecnicamente viáveis.

Tem-se observado que a exigência de aminoácidos sulfurados pode ser afetada por fatores como nível protéico das rações, os sistemas de alimentação, a capacidade genética dos suínos e a relação entre outros aminoácidos limitantes, que podem influenciar diretamente as necessidades de metionina para suínos nas diferentes fases do ciclo produtivo. Dados de pesquisas relativos às exigências de metionina + cistina, com base na taxa de acúmulo de proteína ou na capacidade do suíno em produzir carcaça magra, são pouco referenciados.

Assim, determinou-se a exigência de metionina + cistina digestível para suínos machos castrados e fêmeas de $15 \mathrm{a} 30 \mathrm{~kg}$.

\section{Material e Métodos}

O experimento foi conduzido no Setor de Suinocultura do Departamento de Zootecnia, do Centro de Ciências
Agrárias da Universidade Federal de Viçosa, em Viçosa, MG, no período de maio a setembro de 2004.

Foram utilizados 50 leitões mestiços (Landrace x Large White), sendo 25 leitões machos castrados e 25 fêmeas, em fase inicial de crescimento, com peso inicial de $15,14 \pm 0,42 \mathrm{~kg}$ e 49,50 $\pm 2,63$ dias de idade, distribuídos em delineamento experimental de blocos ao acaso, com cinco tratamentos $(0,502 ; 0,530 ; 0,558 ; 0,586 ; 0,614 \%$ de metionina + cistina digestível, correspondendo a relações 54,$0 ; 57,0 ; 60,0$; 63,$0 ; 66,0 \%$ de metionina + cistina digestível:lisina digestível), cinco repetições e dois animais, um de cada sexo, por gaiola, considerada a unidade experimental. $\mathrm{Na}$ formação dos blocos, foram considerados o peso inicial, o grau de parentesco e o sexo dos animais.

Os animais foram alojados em salas de alvenaria com janelas de vidro do tipo basculante, com cobertura de telha de cerâmica e piso de concreto, sendo alojados em baias de piso baixo com $2 \mathrm{~m}$ de comprimento, 1,20 $\mathrm{m}$ de largura e $0,70 \mathrm{~m}$ de altura, providas de comedouros semi-automáticos e bebedouros tipo chupeta.

As dietas experimentais, isoenergéticas e isoprotéicas (Tabela 1), foram formuladas para atender as exigências dos animais em aminoácidos, energia, minerais e vitaminas, de acordo com as exigências descritas por Rostagno et al. (2000), com exceção dos níveis de metionina + cistina digestível, que foram obtidos a partir da inclusão de DL-metionina 99,0\% em substituição ao amido.

As rações e a água foram fornecidas à vontade aos animais. As rações foram pesadas antes do fornecimento e os resíduos de ração do chão foram coletados diariamente e somados às sobras do comedouro ao final do experimento.

Os animais permaneceram no experimento até atingirem $30,0 \pm 0,32 \mathrm{~kg}$. Após jejum alimentar por 24 horas, um animal de cada unidade experimental com o peso mais próximo de $30 \mathrm{~kg}$ foi abatido por sangramento após dessensibilização, sendo, em seguida, depilado e eviscerado.

As carcaças foram divididas longitudinalmente e a meia-carcaça esquerda, incluindo pés e cabeça, sem as vísceras e o sangue, foi triturada por 15 minutos em cutter comercial de $30 \mathrm{HP}$ e $1.775 \mathrm{rpm}$. Após homogeneização do material triturado, foram retiradas amostras, as quais foram conservadas a $-12^{\circ} \mathrm{C}$ para posterior determinação das deposições diárias de proteína e gordura.

As amostras foram submetidas à pré-secagem em estufa de ventilação forçada, $\mathrm{a} \pm 60^{\circ} \mathrm{C}$ por 72 horas. Em razão da alta concentração de gordura do material, foi realizado prédesengorduramento pelo método a quente, em aparelho extrator do tipo "Soxlet", por 4 horas. As amostras présecas e pré-desengorduradas foram moídas e acondicionadas em vidros devidamente identificados, para posteriores 
Tabela 1 - Composições centesimais e calculadas das dietas experimentais Table 1 - Ingredient and calculated compositions of the experimental diet

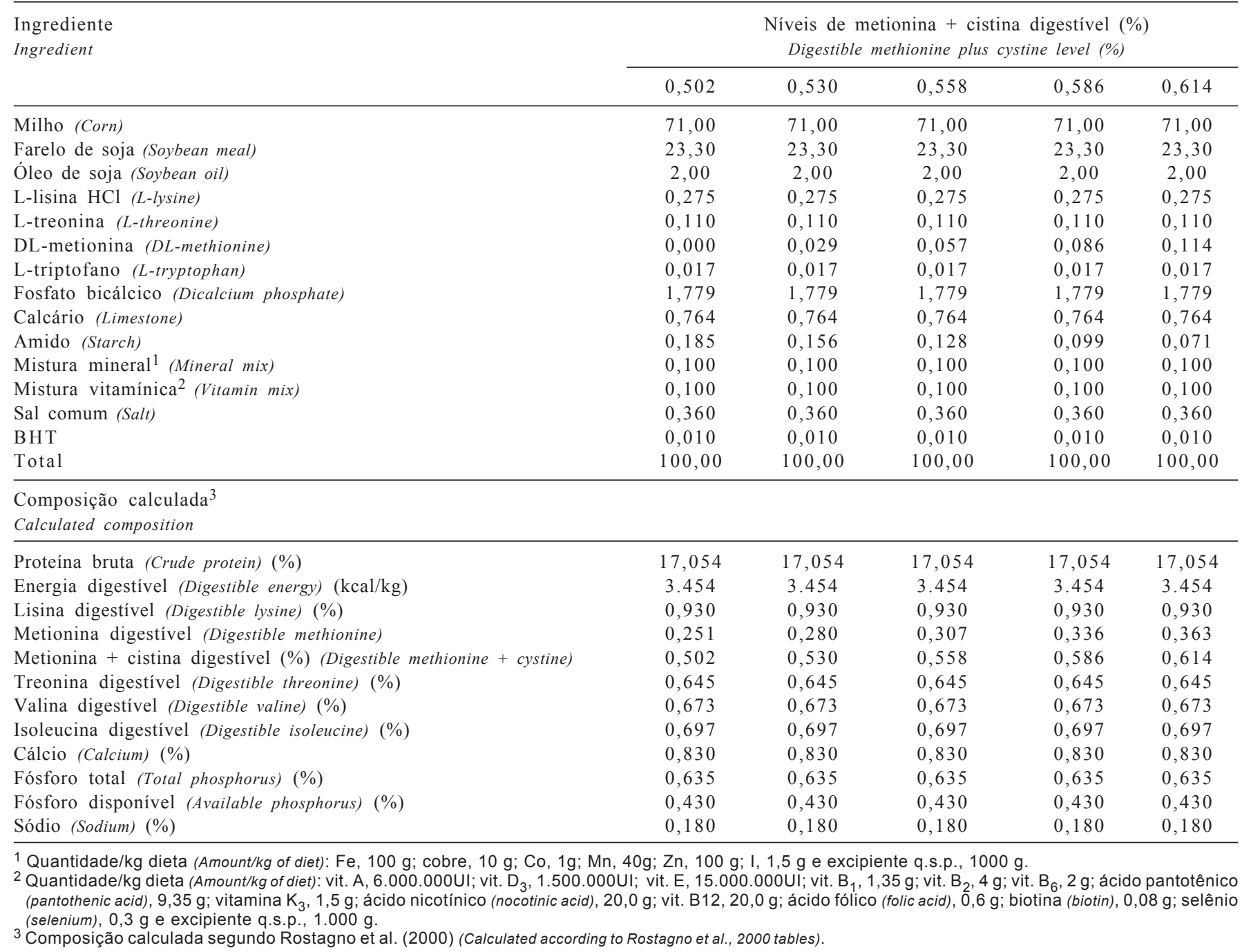

análises laboratoriais. Foram consideradas a água e a gordura retiradas no preparo das amostras para correção dos valores das análises subseqüentes.

As análises bromatológicas de proteína e EE das amostras das carcaças foram realizadas no Laboratório de Nutrição Animal do Departamento de Zootecnia da UFV, de acordo com técnicas descritas por Silva (1990).

Um grupo adicional de cinco leitões com $16,0 \pm 0,37 \mathrm{~kg}$ foi abatido pelo procedimento descrito anteriormente, para determinação da composição da carcaça dos animais no início do experimento.

Os valores da composição das carcaças dos animais no início e no fim do período experimental foram comparados para a determinação das deposições diárias de proteína e gordura na carcaça.

As análises estatísticas das variáveis de desempenho (ganho de peso, consumo de ração e conversão alimentar) e das taxas de deposição de proteína e gordura nas carcaças foram realizadas utilizando-se o programa computacional SAEG(UFV, 1997).

A estimativa da exigência de metionina foi feita com base nos resultados de desempenho e nas taxas de deposição de proteína e gordura na carcaça, utilizando-se os modelos de regressão linear quadrática e o "Linear Response Plateau"-LRP, conforme o melhor ajuste.

\section{Resultados e Discussão}

Os resultados de desempenho, consumo de metionina + cistina digestível e de deposições diárias de proteína e gordura na carcaça dos suínos machos castrados e das fêmeas encontram-se na Tabela 2.

Os níveis de metionina + cistina digestível da dieta influenciaram $(\mathrm{P}<0,01)$ o ganho de peso diário (GPD) dos suínos, que variou de forma quadrática, aumentando até o nível estimado de $0,582 \%$ (Figura 1). Estes resultados 
estão de acordo com os obtidos por Vieira Vaz et al. (2004), que verificaram efeito quadrático dos níveis de metionina + cistina digestível da ração sobre o GPD de suínos de 15 a $30 \mathrm{~kg}$ mantidos em ambiente de termoneutralidade.

Aumento no ganho de peso também foi observado por Chung \& Baker (1992), que verificaram efeito quadrático dos níveis de metionina + cistina digestível da ração sobre o GPD de suínos de 5 a $20 \mathrm{~kg}$, e por Kiefer et al. (2005b), que observaram variação similar do GPD de suínos de 30 a $60 \mathrm{~kg}$ mantidos em ambiente de termoneutralidade, em razão do aumento dos níveis de metionina + cistina da ração.

Leibholz (1984) também observou aumento no GPD de suínos na fase inicial de crescimento, em função da suplementação de metionina + cistina digestível na ração.

$\mathrm{O}$ aumento do ganho de peso entre os níveis 0,502 a $0,582 \%$ de aminoácidos sulfurados digestíveis estaria indicando que houve melhora gradativa no balanço aminoacídico da ração, quando a relação metionina + cistina digestível com a lisina digestível aumentou de $54 \%$, correspondente a $0,502 \%$, para $63 \%$, correspondente a $0,582 \%$ de metionina + cistina.

Houve efeito $(\mathrm{P}<0,01)$ dos níveis de metionina + cistina digestível sobre o consumo diário de ração (CDR), que aumentou de forma quadrática até o nível estimado de 0,579\% (Figura 2), correspondente a uma relação com a lisina digestível de $62 \%$.

Esses resultados diferem dos obtidos por Vieira Vaz et al. (2004) e Veira Vaz et al. (2005), que não notaram variação no CRD de suínos mantidos dos 15 aos $30 \mathrm{~kg}$ em diferentes ambientes com o aumento dos níveis de metionina + cistina digestível da dieta.

Com base nos dados de CRD obtidos neste trabalho, pode-se inferir que o possível desbalanço de aminoácidos da ração, causado pela deficiência ou pelo excesso de metionina + cistina, influenciou negativamente o consumo voluntário na fase inicial de crescimento.

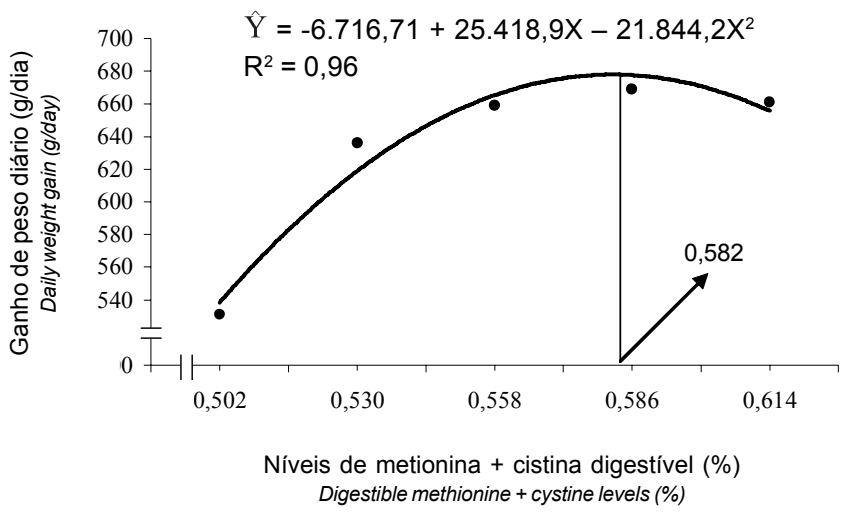

Figura 1 - Representação gráfica do ganho de peso diário de leitões machos castrados e fêmeas (15 a $30 \mathrm{~kg}$ ), em função dos níveis de metionina + cistina digestível das dietas.

Figure 1 - Graphic representation of weight gain according to the dietary levels of digestible methionine plus cystine of barrows and gilts from 15 to $30 \mathrm{~kg}$.

A diminuição do CRD dos leitões em resposta aos dois maiores níveis de aminoácidos sulfurados não confirma o relato de Edmonds \& Baker (1987) de que os suínos podem tolerar considerável excesso de metionina, não apresentando variação significativa no consumo de ração.

Como observado por Santos et al. (2004) em experimento com suínos na fase de terminação, não houve efeito da variação dos níveis de metionina + cistina sobre o CDR dos animais, indicando que os suínos na fase inicial de crescimento são mais sensíveis ao possível desbalanço de aminoácidos da ração causado pelos aminoácidos sulfurados.

Os níveis de metionina + cistina influenciaram $(\mathrm{P}<0,02)$ a conversão alimentar (CA) dos animais, que melhorou de forma quadrática até o nível estimado de $0,588 \%$ (Figura 3 ), correspondendo a uma relação aminoácidos sulfurados digestível:lisina digestível de 63\%. Efeito semelhante dos níveis de metionina + cistina sobre a eficiência de utilização do alimento para ganho de peso também foi observado por

Tabela 2 - Resultados de desempenho, consumo de metionina + cistina digestível e deposições de proteína e gordura na carcaça de suínos machos castrados e fêmeas de 15 a $30 \mathrm{~kg}$, em função do nível de metionina + cistina na dieta

Table 2 - Values of performance, digestible methionine plus cystine intake and daily protein and fat depositions in the carcass of barrows and gilts from 15 to $30 \mathrm{~kg}$ according to the dietary levels of digestible methionine plus cystine

\begin{tabular}{|c|c|c|c|c|c|c|}
\hline \multirow[t]{2}{*}{$\begin{array}{l}\text { Variável }(\%) \\
\text { Variable }\end{array}$} & \multicolumn{5}{|c|}{$\begin{array}{l}\text { Níveis de metionina }+ \text { cistina digestível (\%) } \\
\text { Digestible methionine plus cystine level (\%) }\end{array}$} & \multirow[t]{2}{*}{ CV $(\%)$} \\
\hline & 0,502 & 0,530 & 0,558 & 0,586 & 0,614 & \\
\hline Ganho de peso $^{1}$ (g/dia) (Weight gain, g/day) & 531,0 & 636,0 & 659,0 & 669,0 & 661,0 & 2,93 \\
\hline Consumo de ração ${ }^{1}$ (g/dia) (Feed intake, g/day) & 1020,0 & 1156,0 & 1190,0 & 1180,0 & 1178,0 & 2,57 \\
\hline Conversão alimentar ${ }^{2}(\mathrm{~g} / \mathrm{g})$ (Feed:gain ratio, g/g) & 1,92 & 1,82 & 1,80 & 1,76 & 1,78 & 2,72 \\
\hline $\begin{array}{l}\text { Consumo de met }+ \text { cist } \text { digest }^{3}(\mathrm{~g} / \mathrm{dia}) \text { (Digestible met }+ \text { cys intake, g/day) } \\
\text { Deposição na carcaça (Deposition in the carcass) }\end{array}$ & 5,12 & 6,13 & 6,65 & 6,92 & 7,23 & 2,50 \\
\hline Proteína (g/dia) (Protein, g/day) & 114 & 114 & 121 & 109 & 113 & 7,67 \\
\hline Gordura $^{1}$ (g/dia) (Fat, g/day) & 169 & 148 & 144 & 163 & 165 & 8,61 \\
\hline
\end{tabular}

\footnotetext{
1 Efeito quadrático $(P<0,01) ;{ }^{2}(P<0,02)$, respectivamente; ${ }^{3}$ Efeito linear $(P<0,01)$
}

1 Quadratic effect $(P<0.01),{ }^{2}(P<0.02)$ respectively; ${ }^{3}$ Linear effect $(P<0.01)$. 


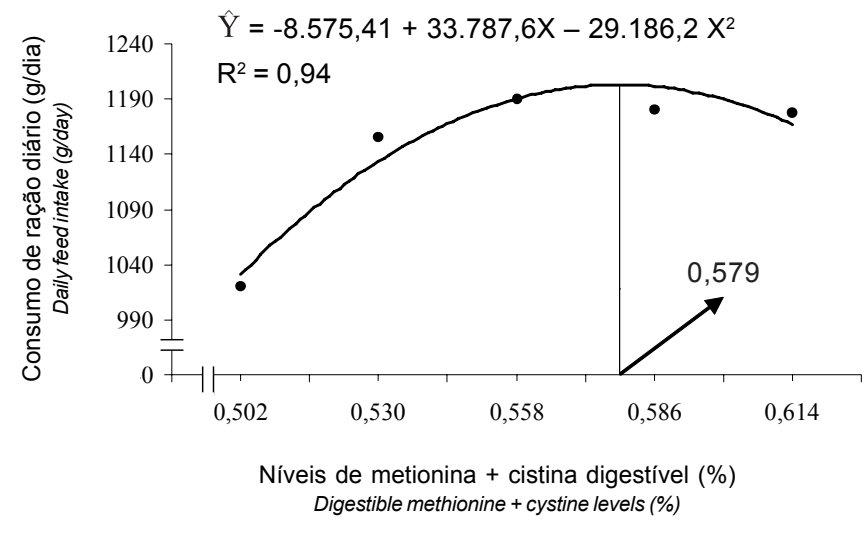

Figura 2 - Representação gráfica do consumo diário de ração, em função dos níveis de metionina + cistina digestível das dietas de leitões machos castrados e fêmeas de 15 a $30 \mathrm{~kg}$.

Figure 2 - Graphic representation of feed intake according to the dietary levels of digestible methionine plus cystine of barrows and gilts from 15 to $30 \mathrm{~kg}$.

Chung \& Baker (1992), em estudo com suínos de 5 a 20 kg, e por Vieira Vaz et al. (2004), em experimento com leitões de 15 a $30 \mathrm{~kg}$ em ambiente termoneutro.

No entanto, ao contrário dos resultados descritos por Vieira Vaz et al. (2005), em que a exigência de aminoácidos sulfurados para melhorar a CA dos animais ficou acima da necessária para maximizar o GP, neste estudo, as melhores respostas de GP e CA foram obtidas em níveis semelhantes de aminoácidos sulfurados $(0,582$ e $0,588 \%)$.

A partir dos resultados de CA, ficou evidenciado que o aumento verificado no ganho de peso até o nível de $0,582 \%$ de metionina + cistina foi mais que proporcional ao do consumo de ração, indicando que, além de aumentar o ganho de peso, os níveis dos aminoácidos sulfurados, provavelmente, alteraram a composição do ganho dos animais.

A relação metionina + cistina digestível:lisina digestível que promoveu os melhores resultados de ganho de peso (63\%) e conversão alimentar (63\%) está acima da relação de $60 \%$ proposta por Chung \& Baker (1992) e por Rostagno et al. (2000).

O consumo diário de metionina + cistina (CMC) aumentou de forma linear $(\mathrm{P}<0,01)$ segundo a equação: $\hat{Y}=-3,58745+17,9109 X\left(R^{2}=0,92\right)$. Aumento linear no consumo de metionina + cistina em função de seus níveis na dieta também foi observado por Kiefer et al. (2005a), Viera Vaz et al. (2004) e Viera Vaz et al. (2005). Esse maior CMC pode ser atribuído ao aumento quadrático do CDR e aos níveis crescente de metionina nas dietas experimentais.

Não se observou efeito $(\mathrm{P}>0,05)$ da suplementação de metionina + cistina sobre a deposição de proteína na carcaça (DPC). Este resultado diverge do obtido por Vieira Vaz et al. (2004), que verificaram aumento na deposição de proteína

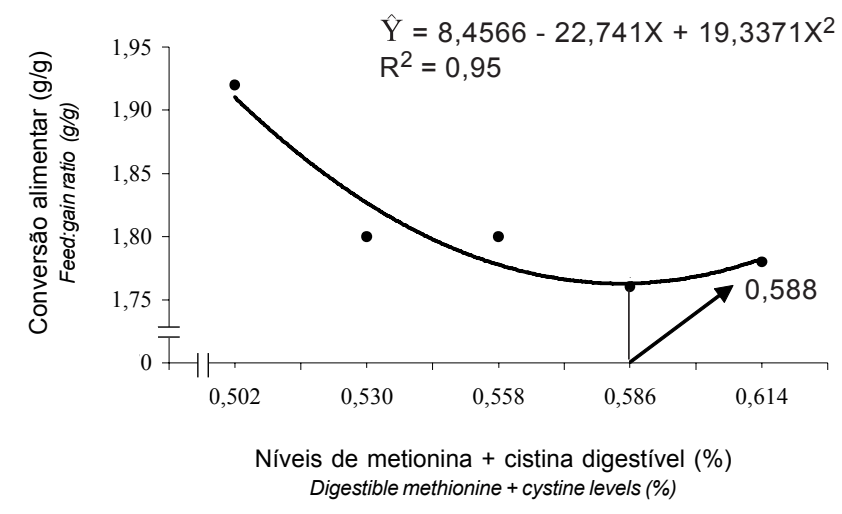

Figura 3 - Representação gráfica da conversão alimentar em função dos níveis de metionina + cistina digestível nas dietas de leitões machos castrados e fêmeas dos 15 aos $30 \mathrm{~kg}$.

Figure 3 - Graphic representation of feed:gain ratio according to the dietary levels of digestible methionine plus cystine of barrows and gilts from 15 to $30 \mathrm{~kg}$.

na carcaça dos suínos de 15 a $30 \mathrm{~kg}$ mantidos em ambiente termoneutro, em resposta aos níveis crescentes de metionina + cistina da ração, atingindo o ponto máximo no nível estimado de $0,630 \%$. Efeito positivo do nível de aminoácidos sulfurados da ração sobre a DPC na carcaça de suínos em crescimento mantidos em ambiente de termoneutro foi observado por Kiefer et al. (2005b).

A resposta de DPC aos níveis crescentes de aminoácidos sulfurados observada neste estudo não está de acordo com a melhora ocorrida no GP e na CA dos animais, visto que o aumento na deposição de proteína, por agregar $35,0 \%$ de água, é um dos principais fatores para justificar esse resultado.

A deposição diária de gordura (DG) na carcaça variou de forma quadrática $(\mathrm{P}<0,01)$, reduzindo até o nível estimado de $0,556 \%$ (Figura 4), que corresponde a uma relação de $60 \%$ com a lisina digestível. Estes resultados foram semelhantes aos obtidos por Vieira Vaz et al. (2005), que observaram variação quadrática na DGD nos suínos em similar faixa de peso mantidos em ambiente de estresse por calor, como conseqüência do aumento dos níveis de metionina + cistina na ração. Por outro lado, em estudo realizado com animais em ambiente termoneutro, Vieira Vaz et al. (2004) não encontraram variação significativa na DGD em função dos níveis de aminoácidos sulfurados da ração.

Estes resultados indicam que o padrão de resposta (deposição de gordura na carcaça) aos níveis crescentes de aminoácidos sulfurados na ração dos suínos em crescimento pode variar de acordo com o ambiente térmico a que os animais estão expostos.

Entretanto, as variações entre as exigências de metionina + cistina digestível e das relações de metionina + cistina 


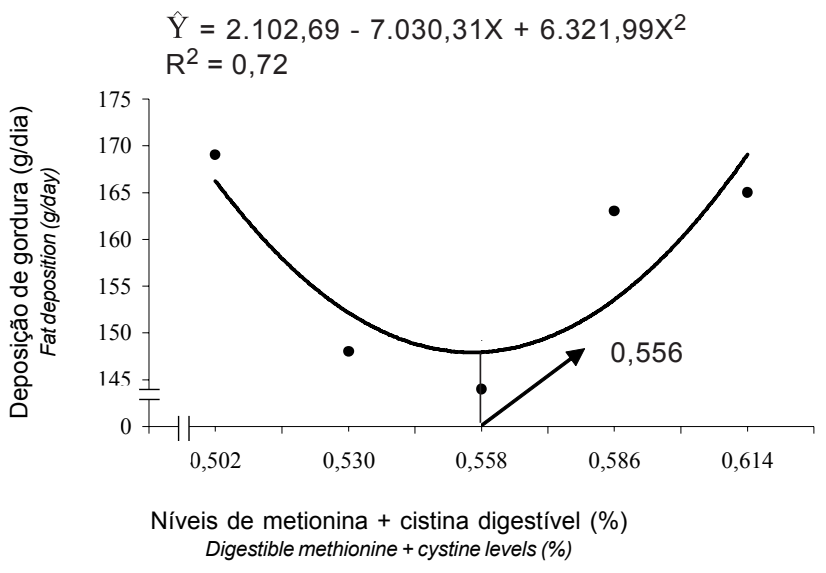

Figura 4 - Efeitos dos níveis de metionina + cistina digestível das dietas sobre a deposição diária de gordura em leitões machos castrados e fêmeas de 15 a $30 \mathrm{~kg}$.

Figure 4 - Graphic representation of daily fat deposition according to the dietary levels of digestible methionine plus cystine of barrows and gilts from 15 to $30 \mathrm{~kg}$.

digestível:lisina digestível observadas entre os trabalhos podem também ocorrer em função da genética, das diferentes faixas de peso dos animais, dos critérios de análises estatísticas adotados, das diferentes condições de temperatura e umidade do ar e dos níveis de aminoácidos usados nas dietas experimentais, principalmente de lisina, e o status sanitário dos animais.

Embora o desafio imunológico possa provocar alterações metabólicas nos suínos, com efeitos negativos sobre o desempenho e a composição de carcaça, a metionina tem sido referendada como um dos principais aminoácidos precursores de imunoglobulinas e cisteína e, segundo Obled (2003), é o aminoácido utilizado durante processos inflamatórios para a síntese de componentes antioxidantes importantes, como a glutationa. Portanto, pode-se deduzir que os animais estavam sob baixo desafio, o que pode explicar, em parte, os resultados obtidos para DG.

Considerando os resultados de DG obtidos neste estudo, ficou evidenciado que, além do ganho de peso e da conversão alimentar, os níveis de metionina + cistina digestíveis influenciaram também a composição de ganho, reduzindo a deposição de gordura na carcaça, o que, em parte, explica os resultados de CA, indicando que o nível de metionina + cistina de $0,556 \%$, que corresponde a uma relação de $60 \%$ de metionina + cistina digestível:lisina digestível para minimizar a deposição de gordura na carcaça, atendeu às exigências de suínos machos castrados e fêmeas na fase de crescimento.

\section{Conclusões}

A exigência de aminoácidos sulfurados digestíveis para suínos machos castrados e fêmeas de 15 a $30 \mathrm{~kg}$ é de
$0,582 \%$, para melhor ganho de peso, e de $0,588 \%$ de metionina + cistina digestível, para melhor conversão alimentar, o que corresponde a uma relação de $63 \%$ de metionina + cistina digestível:lisina digestível.

\section{Literatura Citada}

CHUNG, T.K.; BAKER, D.H. Methionine requirement of pigs between 5 and $20 \mathrm{k}$ kilogramsbody weight. Journal of Animal Science, v.70, p.1857-1863, 1992.

EDMONDS, M.S.; BAKER, D.H. Amino acid excesses for young pigs: effects of excess methionine, tryptofhan, treonine or leucine. Journal of Animal Science, v.64, p.1664-1671, 1987.

EDMONDS, M.S.; GONYOU, H.W.; BAKER, D.H. Effect of excess levels of excess methionine, tryptofhan, arginine, lysine or threonine on growth and dietary choice in the pig. Journal of Animal Science, v.65, p.179-185, 1987.

KIEFER, C.; FERREIRA, A.S; OLIVEIRA, R.F.M. et al. Exigência de metionina mais cistina digestíveis para suínos machos castrados mantidos em ambiente de alta temperatura dos 30 aos $60 \mathrm{~kg}$. Revista Brasileira de Zootecnia, v.34, n.1, p.104$111,2005 \mathrm{a}$.

KIEFER, C.; FERREIRA, A.S.; DONZELE, J.L. et al. Exigência de metionina + cistina digestíveis para suínos mantidos em ambiente termoneutro dos 30 aos $60 \mathrm{~kg}$. Revista Brasileira de Zootecnia, v.34, n.3, p.847-854, 2005b.

LEIBHOLZ, J. A note on the influence of methionine content in the diet of pigs from 21 to 49 days of age on their performance from 49 to 97 days of age. Animal Production, v.39, p. 153,1984

NONES, K. Efeito da formulação da dieta sobre o desempenho, qualidade de carcaça poder poluente dos dejetos de suínos nas fases de crescimento e terminação. Pelotas: Universidade Federal de Pelotas, 1999. 90p. Dissertação (Mestrado em Zootecnia) - Universidade Federal de Pelotas, 1999.

OBLED, C. Necessidades de aminoácidos em estados inflamatórios. In: CURSO DE ESPECIALIZAÇÕES FEDNA, 19., 2003, Madrid. Proceedings... Madrid: INRA, Uniti de Nutrition et Metabolisme Proteique, 2003. p.73-88.

ROSTAGNO, H.S.; ALBINO, L.F.T.; DONZELE, J.L. et al. Composição de alimentos e exigências nutricionais de aves e suínos: tabelas brasileiras. Viçosa, MG: Universidade Federal de Viçosa, 2000. 141p.

SANTOS, F.A.; DONZELE, J.L.; SILVA, F.C.O. et al. Exigências de metionina mais cistina digestíveis para suínos machos castrados de alto potencial genético para deposição de carne magra, dos 60 aos $95 \mathrm{~kg}$. In: REUNIÃO ANUAL DA SOCIEDADE BRASILEIRA DE ZOOTECNIA, 41., 2004, Campo Grande. Anais... Campo Grande: 2004 (CD-ROM).

SILVA, D.J. Análise de alimentos (métodos químicos e biológicos) Viçosa, MG: Universidade Federal de Viçosa, 1990. 165p.

VIEIRA VAZ, R.G.M.; OLIVEIRA, R.F.M: DONZELE, J.L. et al. Exigências de aminoácidos sulfurados digestíveis para suínos machos castrados mantidos em ambientes termoneutro dos 15 aos $30 \mathrm{~kg}$. In: REUNIÃO ANUAL DA SOCIEDADE BRASILEIRA DE ZOOTECNIA, 41., 2004, Campo Grande. Anais... Campo Grande: 2004 (CD-ROM).

VIEIRA VAZ, R.G.M.; OLIVEIRA, R.F.M.; DONZELE, J.L. et al. Exigências de aminoácidos sulfurados digestíveis para suínos machos castrados mantidos em ambientes de alta temperatura dos 15 aos 30 kg. Revista Brasileira Zootecnia, v.34, n.5, p.1633-1639, 2005.

UNIVERSIDADE FEDERAL DE VICCOSA - UFV. SAEG - Sistemas de Análises Estatísticas e Genéticas (Manual de utilização do programa). Viçosa, MG: UFV, 1997. 150p.

Recebido: 06/06/05 Aprovado: 15/12/05 